\title{
Insulina una vez por semana para los diabéticos tipo $2^{\prime \prime \prime}$
}

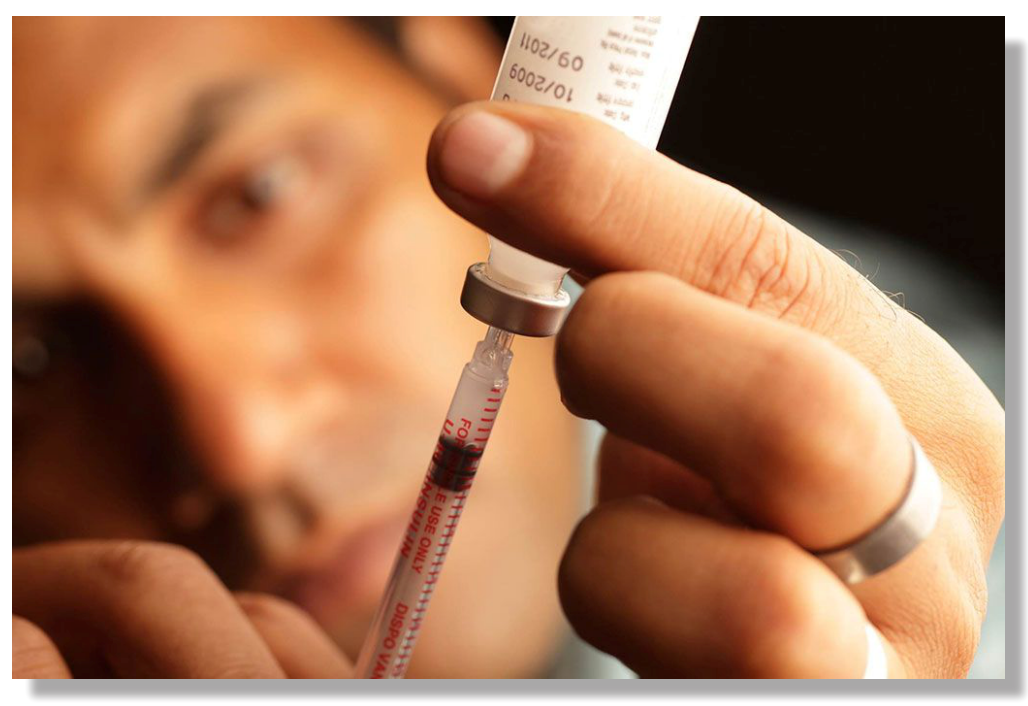

Se sabe que reducir la frecuencia de la insulina basal facilita el tratamiento y la adeción en diabéticos tipo 2.

La insulina icodec es un análogo de la insulina basal designado para ser usado una vez por semana y que está en desarrollo para el tratamiento de la diabetes.

247 pacientes fueron divididos para utilizar glargina o icodec cuyas características fueron similares.
En cambio la hemoglobina glicosilada fue de menos 1.33 en el grupo icodec y 1.5 en el grupo glargina.

No hubo diferencias en los aspectos adversos entre ambas insulinas.

Se concluye que tienen la misma eficacia y seguridad.

Rolando Calderón-Velasco

1. Rosenstock, J. et al. N Engl J Med 2020;383:2007-

Citar como: Calderón-Velasco R. Revista de Revistas. Insulina una vez por semana para los diabéticos tipo 2. Diagnóstico(Lima). 2020;59(4):222.

DOI: 10.33734/diagnostico.v59i4.263

Correspondencia: Rolando Calderón Velasco. Correo electrónico: rocalve@gmail.com

\section{Fundación INSTITUTO Hipólito UNANUE}

$$
\text { •fihu-diagnostico@alafarpe.org.pe •www.fihu.org.pe }
$$

